\title{
Crônica de uma crise anunciada: o Brasil paralisado sobre rodas
}

Gustavo Cruz de Sousa Júnior ${ }^{1}$

\section{Resumo}

A greve dos caminhoneiros iniciada em 21 de maio de 2018, também chamada de Crise do Diesel, foi a maior paralisação da categoria em toda a história brasileira, estendendo-se por dez dias consecutivos e levando o Brasil, um país que utiliza majoritariamente a matriz rodoviária para o transporte de cargas, próximo a um colapso no fornecimento de produtos e serviços. Na pauta de reivindicações dos grevistas, figuravam questões como a redução no preço do diesel e o fim da política de reajuste de preços implementada pela Petrobras, que atrelava o preço dos combustíveis à cotação da moeda norte-americana. 0 presente artigo pretende estudar como os caminhoneiros se mobilizaram e se estruturaram durante o período que antecedeu a greve e durante esta, bem como analisar sua atuação durante todo o conflito. Considerando-se as múltiplas facetas dos atores envolvidos na iniciativa de interromper o transporte de cargas no país - empresários, trabalhadores autônomos e empregados -, será inicialmente feita a identificação de classe, tomando por base a tipologia de classes de Erik Wright, para se compreender efetivamente quem são os caminhoneiros. 0 conceito de ethos de posição será utilizado, ainda, para se entender de que forma elementos, a exemplo da solidariedade de classe, contribuíram para se chegar a um cenário de conflito. Posteriormente, à luz da Teoria das Ações Coletivas Conflitivas de Guy Bajoit, observados os processos de privação, frustração, mobilização e organização, serão analisadas as ações empreendidas pelos atores societais envolvidos na luta contra os movimentos envidados pelos atores estatais na tentativa de pôr um fim à paralisação.

\section{Palavras-chave}

Ações coletivas conflitivas. Ethos de posição. Mobilização.

\section{Abstract}

The truckers' strike that began on May 21,2018, also called the Diesel Crisis, was the largest standstill of the kind in all Brazilian history, extending for ten consecutive days and taking Brazil, a country that relies mostly on cargo transportation, close to a collapse in the supply of products and services. The strikers' claims list included issues such as the reduction of the diesel price and the end of the policy of price adjustment implemented by Petrobras, which tied the price of fuel to the US currency

\footnotetext{
${ }^{1}$ Gustavo Cruz de Sousa Júnior é doutorando em Ciências Sociais da Universidade do Vale do Rio dos Sinos - UNISINOS. E-mail: gustavo.sousa@gmail.com.
} 
quotation. The present article intends to study how the truck drivers mobilized and structured themselves during the time before and during the strike, as well as analyzing ho they performed throughout the conflict. Considering the multiple facets of the actors involved in the initiative to interrupt the transportation of cargo in the country - entrepreneurs, self-employed workers, and employees -, class identification will be made initially, based on the class typology of Erik Wright, to understand effectively who the truckers are. The concept of the position ethos will also be used to understand how elements such as class solidarity contributed to the outcome of a scenario of conflict. Later, considering Guy Bajoit's Theory of Conflictive Collective Actions, observing the processes of deprivation, frustration, mobilization and organization, the article will analyze the actions taken by the societal actors involved in the struggle against the movements made by the state actors to put an end to the standstill.

\section{Keywords}

Conflicting collective actions. Position ethos. Mobilization.

\section{Introdução}

Maio de 2018 ficou marcado na história brasileira como sendo o mês em que o transporte rodoviário brasileiro parou diante da maior greve de caminhoneiros já registrada. Por dez dias, o País sofreu com rodovias bloqueadas para o tráfego de cargas, o que culminou com o desabastecimento de itens básicos - incluindo alimentos, combustíveis e gás de cozinha - em todas as 27 unidades da Federação e com a queda do presidente da empresa estatal Petrobras. Porém, mesmo diante de uma situação caótica que se espraiou pelas cinco regiões brasileiras, os manifestantes conquistaram relativo apoio popular e, ao fim, a abertura do diálogo com o Governo Federal, que até então se mostrava impassível, bem como o atendimento a seus principais pleitos.

O presente artigo pretende realizar uma leitura crítica da greve dos caminhoneiros, analisando como estes se mobilizaram e se estruturaram, suas reivindicações, chegando à etapa do conflito, tendo aqui os atores estatais como opositores. O objetivo é evidenciar a pertinência do enfoque que propõe sobre o tema em seus fundamentos teóricos e em suas possibilidades interpretativas.

Como ponto de partida, será feita a identificação de classe da categoria empírica a partir da tipologia de classes de Wright (2015). Esta etapa, embora não seja suficiente para, de maneira isolada, explicar o fenômeno social em si, é fundamental para a identificação de elementos, a exemplo da construção de uma cultura de classe, que, como se verá mais adiante, foram determinantes para a 
união de diferentes profissionais ligados ao setor do transporte em torno de uma mesma pauta bem como para o sucesso do movimento.

Em seguida, à luz da Teoria das Ações Coletivas Conflitivas de Bajoit e Vanhust (2017), se buscará examinar as ações envidadas pelos atores societais envolvidos. Nessa perspectiva serão observadas, no caso em tela, as dezoito condições para os três principais processos de ação coletiva, segundo o referencial teórico proposto pelos autores: i) a etapa que vai da privação à frustração, ii) a etapa que vai da frustração à mobilização e, por fim, iii) a fase que contempla a evolução da mobilização à organização.

Do ponto de vista cronológico, a paralisação foi o clímax de uma crise que teve início ainda em 2015, quando caminhoneiros realizaram a primeira greve geral por uma pauta que, já naquela ocasião, demandava, principalmente, a redução no preço do combustível, além de melhores condições de trabalho. Fruto das manifestações à época, o Governo Federal, que tinha como presidente da República Dilma Rousseff, publicou decreto que se transformaria na Lei $\mathrm{n}^{\circ} 13.103$, de 2 de março de 2015, popularmente conhecida como Lei dos Caminhoneiros.

Porém, em outubro de 2016, com a mudança na política de precificação da Petrobras (PETROBRAS, 2016), a tabela de preços da empresa - que detém o monopólio sobre a distribuição de combustíveis no País - passou a acompanhar a flutuação internacional do valor do petróleo, cotado em dólares. Até então, o preço sofria interferências do Governo, que chegava a determinar a venda do produto abaixo do valor de mercado como forma de conter a inflação. Com a mudança na precificação associada à desvalorização do Real frente à moeda americana, o preço dos combustíveis para o consumidor final disparou, sofrendo reajustes frequentes, às vezes na mesma semana. Essa situação afetou sobremaneira o mercado de transporte, uma vez que o combustível é um componente dos mais importantes no cálculo do preço dos fretes, trazendo à tona o sentimento de descontentamento e comprometendo a lealdade (BAJOIT, 1988, p. 328) estabelecida desde os protestos do ano anterior. Segundo dados da Agência Nacional de Petróleo (BRASIL, 2018), de outubro de 2016 a maio de 2018, o aumento no preço de revenda do óleo diesel foi de $17,6 \%$, enquanto no período correspondente anterior ${ }^{2}$ à mudança na política de preços o incremento foi de apenas 6,86\%.

Para se ter uma ideia do tamanho do mercado atingido, segundo o Anuário da Confederação Nacional de Transportes - CNT (2017), 61,1\% de toda a carga transportada no Brasil utilizam o modal rodoviário. São 111.743 empresas

\footnotetext{
${ }^{2}$ Considerando o período de 20 meses, de março de 2015 a outubro de 2016.
} 
transportadoras, 11.199 empresas de locação de veículos, 274 cooperativas e 374.029 transportadores autônomos.

Em 16 de maio, a Confederação Nacional dos Transportadores Autônomos CNTA (2018) protocolou ofício endereçado ao presidente Michel Temer e seis ministros de Estado no qual solicitou, em caráter emergencial, o congelamento do preço do óleo diesel e a suspensão da cobrança do eixo suspenso ${ }^{3}$, ou seja, praticamente os mesmos pleitos que conduziram aos protestos de 2015. Se aceitas, as medidas abririam as negociações e poderiam impedir a paralisação, o que evitaria, na perspectiva de Bajoit (1988, p.330), a passagem da apatia à defecção, ou seja, troca da negociação pelo rompimento das relações sociais e de cooperação estabelecidas entre a classe dos transportadores e o Governo.

O ofício da CNTA foi ignorado por parte do Governo Federal e, no dia 18 de maio, foi feito o aviso de que a categoria iniciaria a paralisação no dia 21 daquele mês.

A situação de descontentamento da categoria foi agravada ainda mais pelo reajuste anunciado pela Petrobras no dia 19. O aumento do preço do diesel em $0,80 \%$ e da gasolina em $1,34 \%$ nas refinarias teve como justificativa o aumento internacional dos preços do petróleo.

Houve, ainda, uma tentativa, em 20 de maio, por parte da Justiça Federal, de coibir a manifestação da categoria proibindo o bloqueio total de estradas federais por caminhoneiros, no Paraná. A ação foi movida pela Advocacia-Geral da União (AGU) a pedido da Superintendência da Polícia Rodoviária Federal (PRF). Porém, a iniciativa não surtiu efeito e, no dia seguinte, diante da impossibilidade de negociações demonstrada por parte dos atores estatais, a situação de conflito foi deflagrada com a paralisação de caminhoneiros em 17 das 27 unidades da Federação. Conforme Gaiger (1999, p. 70), “a insuficiência de alternativas [...] gera um descontentamento e uma receptividade à ação coletiva, em razão dos seus resultados efetivos".

Apenas um dia depois, a paralisação já atingia 23 estados mais o Distrito Federal. Esse cenário fez com que o Governo se movimentasse e o ministro da Fazenda, Eduardo Guardia, anunciasse medida para eliminar um dos impostos sobre o diesel até 2020 (CASTILHOS; MATOSO, 2018). A política de preços da Petrobras, no entanto, foi mantida.

Diante da crise estabelecida, a Petrobras anunciou a redução no preço dos combustíveis para as refinarias. As medidas foram inócuas e não minimizaram o cenário de conflito instalado no País, uma vez que a insatisfação da categoria se

\footnotetext{
${ }^{3}$ Essa suspensão refere-se à cobrança da tarifa de pedágio referente ao eixo que não é usado quando o caminhão está vazio.
} 
espraiava para questões de privação que estavam muito além do preço do combustível.

Já no terceiro dia de paralisação, 23 de maio, o desabastecimento se espalhou por todo o Brasil. Diante da escassez de diversos produtos, sobretudo hortifrutigranjeiros, os preços dispararam. Várias indústrias, a exemplo da automotiva, anunciaram redução nas suas linhas de produção. Porém, apesar do cenário do caos instaurado, a paralisação contava parcialmente com o apoio popular, uma vez que a sociedade também se viu representada pela manifestação, na medida em que a política de reajuste da Petrobras atingia a todos. Vale destacar que os grevistas impediam a passagem de caminhões, mas permitiam a passagem de veículos de passeio, de modo que o direito de ir e vir estava garantido.

O presidente Michel Temer, antes inerte aos pleitos dos caminhoneiros, pediu uma "trégua" de três dias para encontrar uma solução adequada. Porém, o pedido não foi atendido e a greve prosseguiu.

No dia 24, o ministro-chefe da Casa Civil, Eliseu Padilha, anunciou que Governo e grevistas tinham chegado a um acordo e que a greve seria suspensa pelo período de 15 dias. Porém, duas entidades de representação de caminhoneiros autônomos, a União Nacional dos Caminhoneiros e a Associação Brasileira dos Caminhoneiros (Abcam), não ratificaram o acordo, e a greve prosseguiu.

Neste ponto, diante do extenso desabastecimento nos mais diversos setores em todo o País, voos foram suspensos, aulas canceladas, e o abastecimento de combustível limitado a veículos destinados a serviços fundamentais, como ambulâncias e segurança pública.

A paralisação só terminou no dia 27, quando finalmente o presidente Michel Temer "anunciou a redução de $\mathrm{R} \$ 0,46$ no litro do diesel por 60 dias, o estabelecimento de uma tabela mínima dos fretes e a isenção da cobrança de pedágio para eixo suspenso de caminhões vazios". (MORENO et al., 2018).

\section{Irresponsáveis, imprudentes e drogados}

Apesar de estar entre as atividades profissionais mais comuns do Brasil, há muitas peculiaridades relativas à profissão dos caminhoneiros que são desconhecidas por aqueles que não compõem esse universo. Deste modo, é fundamental caracterizar o grupo de referência empírica como forma de compreender melhor os fatores que favoreceram a abertura do conflito, bem como identificar elementos que compõem a cultura de classe. "A cultura compreende aqui o conjunto de conhecimentos, valores, modelos de prática e expressões simbólicas assumidos por um indivíduo, uma categoria social ou, mais amplamente, pelos membros de uma sociedade 
determinada." (GAIGER, 1997, p.71).

Essa informação, associada ao conceito de ethos de posição, é relevante para a compreensão do caminho de abandono à lealdade (BAJOIT, 1988) e a opção pelo conflito.

Para esse melhor entendimento da categoria e sua identificação como classe, tomaremos como base a pesquisa realizada pela Confederação Nacional do Transporte (CNT, 2016), denominada Perfil dos Caminhoneiros ${ }^{4}$. A organização divide os profissionais entre caminhoneiros autônomos, ou seja, aqueles que são proprietários de caminhão que trabalham por conta própria ou prestam serviço a uma empresa, e caminhoneiros empregados de frota, aqueles profissionais assalariados, vinculados a uma empresa. Essa distinção ajuda a traçar, a partir da Tipologia de Classes Básica (WRIGHT, 2015), o mapa das posições de classe.

Os campos na tipologia não são "classes" propriamente ditas; são posições dentro das relações de classe. Alguns são posições contraditórias dentro das relações de classe; outros são posições de apropriação privilegiadas dentro das relações de exploração; outras, ainda, são posições polarizadas dentro das relações capitalistas de propriedade. Por convenção, as posições polarizadas - "capitalistas" e "trabalhadores" no capitalismo - costumam ser chamadas de "classes", mas a terminologia mais precisa seria descrevêlas como posições fundamentais na estrutura de classe capitalista. A tipologia não é, portanto, uma proposta de modelo de seis classes para estrutura de classes do capitalismo, e sim um modelo de uma estrutura de classe que diferencia seis posições dentro das relações de classe. (WRIGHT, 2015, p. 147).

Nessa perspectiva, as empresas, compreendendo aqui tanto as transportadoras quanto as locadoras de frota, são classificadas como capitalistas, uma vez que detêm os meios de produção e contratam a força de trabalho (Quadro 1). Do outro lado, há os caminhoneiros autônomos e as cooperativas, que também detêm os meios de produção, mas não contratam a força de trabalho. E há, ainda, os caminhoneiros assalariados, que não detêm os meios de produção e são subordinados à autoridade dos capitalistas.

\footnotetext{
${ }^{4}$ A Pesquisa CNT Perfil dos Caminhoneiros 2016 entrevistou 1.066 profissionais em 12 unidades da Federação com maior frota dentro da região. A coleta de dados foi baseada na amostragem sistemática de caminhoneiros em postos de combustíveis e grandes áreas comerciais predefinidos proporcionalmente distribuídos em 729 autônomos (68,4\%) e 337 empregados de frota (31,6\%). A pesquisa teve margem de erro de 3,0 pontos percentuais com $95 \%$ de nível confiança. O período de coleta foi de 04/11/2015 a 14/11/2015.
} 


\section{Quadro 1 - Tipologia de classe básica - Caminhoneiros}

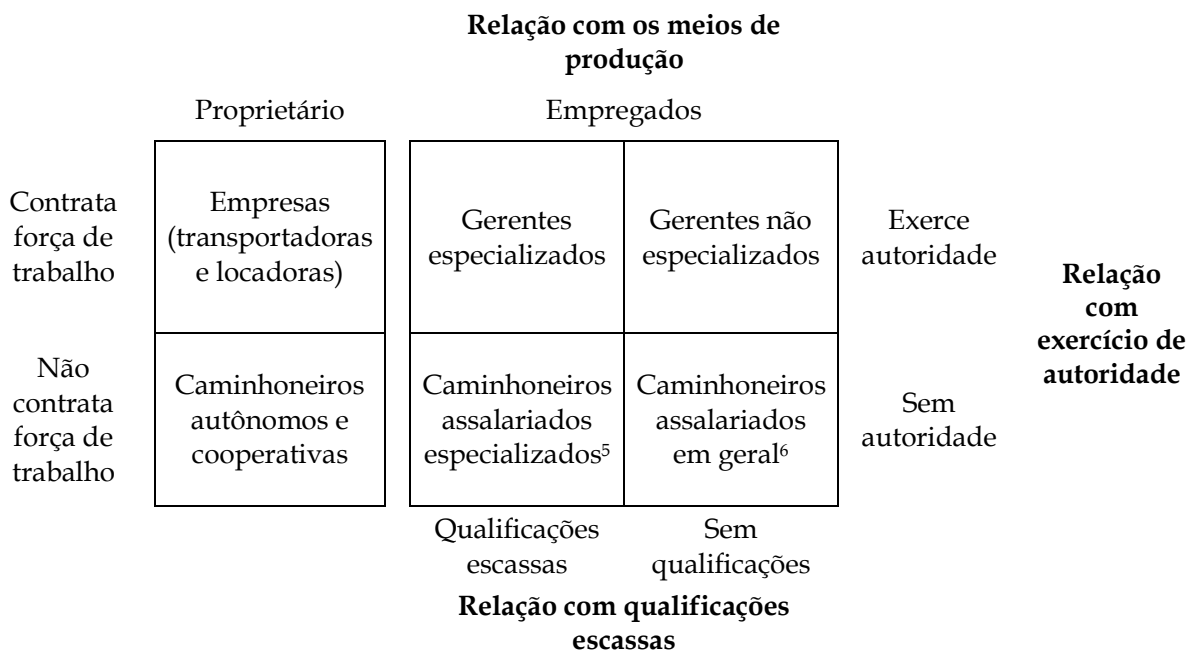

Fonte: Elaborado pelo autor segundo Wright (2015, p.147)

Apesar de os autônomos serem os detentores dos meios de produção, no caso proprietários do caminhão, compreende-se, diante da pauta de reivindicações, tanto estes quanto os caminhoneiros assalariados como integrantes de uma mesma classe, na medida em que o Estado se apresenta como o vetor da exploração de classe ${ }^{7}$. Como explica Wright (2015, p.155), "o termo 'classe' se refere a qualquer grupo de pessoas que se encontre na mesma situação de classe", o que é reconhecido neste contexto. Assevera, ainda, o autor que a relação com o Estado também pode proporcionar essas ligações. Em cada caso, a pergunta a se fazer é "como as relações sociais nas quais a vida de uma pessoa está inserida ligam essa pessoa aos vários mecanismos de exploração de classe e, portanto, moldam seus interesses materiais?" (WRIGHT, 2015, p. 150).

No que diz respeito às características socioeducacionais da categoria, a pesquisa (CNT, 2016) revela que, entre os autônomos, a faixa etária entre 40 e 49 anos é a mais comum (30,7\%). Já os empregados de frota são mais jovens, com maioria $(39,7 \%)$ na faixa dos 30 aos 39 anos. Destaca-se, entretanto, que 80,5\% dos

${ }_{5}$ Compreendendo motoristas profissionais de caminhões pesados, que exigem conhecimento específico para o transporte de cargas.

${ }^{6}$ Compreendendo motoristas profissionais de caminhões leves e de uso prioritariamente urbano.

${ }^{7}$ Na perspectiva marxista (WRIGHT, 2015). 
profissionais estão compreendidos na faixa etária de 30 a 59 anos. A partir desses dados é possível observar que o trabalho assalariado é a porta de entrada para a atividade profissional na medida em que o tipo de caminhoneiro - autônomo ou empregado - é inversamente proporcional à faixa etária.

Os dados ratificam o senso comum de que se trata de uma profissão majoritariamente masculina. Em termos de gênero, 99,8\% dos que atuam na profissão são homens. Essa característica, em particular, contribui com a socialidade primária grupal na medida em que a proximidade de gênero favorece os laços fusionais, a cooperação, a reciprocidade e a solidariedade comunitária e classista, uma vez que a profissão impõe desafios, como a solidão e a privação do convívio familiar - pontos também destacados pela pesquisa - , que são superados pela solidariedade.

Em termos de escolaridade, quase $40 \%$ dos autônomos cursaram o ensino fundamental incompleto. Já no grupo dos empregados de empresas frotistas, o maior grupo é aquele com fundamental completo.

Já no que se refere ao tempo de atuação profissional, a maior parte dos empregados de frota $(23,5 \%)$ tem menos de cinco anos de profissão, enquanto entre os autônomos a distribuição é mais homogênea, sendo o maior grupo aquele que tem entre 16 e 20 anos de atuação profissional $(17,5 \%)$.

Outra questão referente à atuação como caminhoneiro é que $40 \%$ do total $(40,3 \%$ dos autônomos e 39,2\% dos empregados) nunca tiveram outra profissão em toda a sua vida senão a de motorista de caminhão. E entre aqueles $60 \%$ que tiveram outra profissão, 22,8\% trabalharam em outras atividades ligadas ao transporte.

Quanto à jornada de trabalho, considerando os autônomos e os empregados, a maior parte trabalha, em média, entre nove e doze horas diárias. Cerca de 30\% da amostra pesquisada trabalha os sete dias da semana.

Questionados sobre os pontos negativos da sua profissão, $60 \%$ destacaram o perigo e a insegurança como principais desvantagens. Ainda são citados o desgaste, o convívio familiar comprometido, o fato de ser pouco rentável financeiramente, solitária e que exige rotinas árduas de trabalho.

Perguntou-se, ainda, quais os principais entraves no exercício da atividade (Tabela 1). O custo do combustível foi o principal ponto destacado $(46,4 \%)$, seguido do valor do frete $(40,1 \%)$ que, segundo os profissionais, é insuficiente para cobrir os custos. Observa-se aqui que as mesmas pautas que determinaram a paralisação de 2015 continuam presentes, ainda que de forma latente. A despeito da privação imposta pela pelos atores estatais, a lealdade foi mantida. 
Tabela 1 - Principais entraves na atividade do caminhoneiro

\begin{tabular}{|l|c|c|c|}
\hline \multirow{2}{*}{$\begin{array}{c}\text { Problemas na atividade do } \\
\text { caminhoneiro }\end{array}$} & \multicolumn{2}{c|}{ Tipo de caminhoneiro } & \multirow{2}{*}{ Total } \\
\cline { 2 - 3 } & Autônomos & $\begin{array}{c}\text { Empregados } \\
\text { de frota }\end{array}$ & \\
\hline Custo do combustível & 56,4 & 24,9 & 46,4 \\
\hline Valor do frete não cobre os custos & 45 & 29,4 & 40,1 \\
\hline Assaltos e roubos & 31,4 & 51 & 37,6 \\
\hline Custo do pedágio & 21,8 & 14,8 & 19,6 \\
\hline Riscos de acidentes & 12,2 & 33,8 & 19 \\
\hline Deficiência na infraestrutura rodoviária & 13,3 & 22 & 16 \\
\hline Fadiga e estresse & 4,4 & 13,6 & 7,3 \\
\hline Baixa demanda pelo transporte de cargas & 7,7 & 4,7 & 6,8 \\
\hline Outros & 2,1 & 1,5 & 1,9 \\
\hline NS/NR & 0,1 & 0 & 0,1 \\
\hline
\end{tabular}

Fonte: Confederação Nacional do Transporte (CNT, 2016).

A pesquisa revela, ainda, quais as principais reivindicações por parte da categoria. A redução de taxas e impostos no consumo do combustível foi apontada por $66,7 \%$ dos entrevistados, tendo maior relevância entre os autônomos (74,5\%). Entre os empregados, a reivindicação também é o principal item da pauta, mas citado por $49,9 \%$ dos entrevistados.

Comparando-se esses dados com a pauta de reivindicações da paralisação de 2018, pode-se notar claramente a presença dos fatores que culminaram na eclosão da manifestação. Isso corrobora no sentido de demonstrar como a ação coletiva conflitiva parte de um conjunto de elementos que vão se somando ao longo do tempo - da frustração à mobilização (BAJOIT; VANHUST, 2017) - e não de forma abrupta e isolada.

Para compreendermos ainda elementos que compõem a formação do ethos e, ao fim e ao cabo, o processo disruptivo que conduziu à frustração, é relevante a abordagem que também foi feita pela pesquisa da CNT (2016). Buscou-se identificar qual a ideia que os caminhoneiros têm sobre como a categoria é vista pela sociedade.

A respeito da imagem que os caminhoneiros acham que as pessoas têm da sua profissão, para 44,7\% dos profissionais (41,8\% dos autônomos e 50,7\% dos empregados), a sociedade os vê como irresponsáveis (Tabela 2). Destaque-se que entre as cinco características mais citadas as quatro primeiras são negativas: além de irresponsável, imprudentes no trânsito (29,8\%), usuários de drogas (26,5\%), pessoas sem instrução $(24,7 \%)$ e, somente em quinto lugar, importantes para a 
economia do País $(12,6 \%)$.

Tabela 2 - Imagem que as pessoas têm do caminhoneiro

\begin{tabular}{|l|c|c|c|}
\hline \multirow{2}{*}{$\begin{array}{c}\text { Imagem que as pessoas têm do } \\
\text { caminhoneiro }\end{array}$} & \multicolumn{2}{|c|}{ Tipo de caminhoneiro } & \multirow{2}{*}{ Autônomos } \\
\cline { 2 - 3 } & $\begin{array}{c}\text { Empregados de } \\
\text { frota }\end{array}$ & \\
\hline Irresponsável & 41,8 & 50,7 & 44,7 \\
\hline Imprudente no trânsito & 30,6 & 28,2 & 29,8 \\
\hline Usuário de drogas & 24,1 & 31,5 & 26,5 \\
\hline Pessoas sem instrução & 27 & 19,6 & 24,7 \\
\hline Importante para a economia do País & 11,7 & 14,5 & 12,6 \\
\hline Solidário na estrada & 7,1 & 8,3 & 7,5 \\
\hline Comprometido com a profissão & 5,2 & 6,5 & 5,6 \\
\hline Responsável & 2,9 & 4,5 & 5,4 \\
\hline Pouco valor & 2,7 & 0,3 & 2 \\
\hline Outros & 1,2 & 2,7 & 1,7 \\
\hline NS/NR & 3,7 & 5 & 4,1 \\
\hline O caminhoneiro poderia citar mais de 1 item nesta questão & \\
\hline
\end{tabular}

Fonte: Confederação Nacional do Transporte (CNT, 2016).

Outro ponto de relevância levantado pela pesquisa diz respeito à Lei dos Caminhoneiros, aquela que, em 2015, pôs fim às manifestações. Do total de entrevistados, $88,4 \%$ afirmaram conhecer a Lei. Destes que disseram conhecê-la, mais da metade $(54,7 \%)$ disseram que as mudanças na legislação não atendem às necessidades dos caminhoneiros. Outros $38,6 \%$ apontaram que as mudanças atendem parcialmente. E mais: do grupo que disse conhecer a Lei, $61 \%$ afirmaram que a rotina de trabalho continuou a mesma após a aprovação do texto e, para $20,5 \%$, piorou.

Diante dos dados apresentados pela pesquisa em tela, observam-se elementos que favorecem - ou até mesmo asseveram - os vínculos sociais. São necessidades, objetivos pessoais e elementos identitários que se somam compondo um ethos de posição. A imagem negativa que a classe projeta para si por parte da sociedade associada aos problemas materiais e psicossociais enfrentados consolidam a ideia de que o êxito na busca de satisfazer os objetivos pessoais bem como suas necessidades e aspirações só se dará por meio de ações coletivas. 


\section{Uma rodovia para a mobilização}

O caminho que conduziu à frustração e, por fim, à paralisação de 2018 foi pavimentado por um sentimento latente - evidenciado na pesquisa CNT (2016) - de não ter havido mudanças positivas significativas após 2015. Ao contrário, os pleitos continuavam sendo os mesmos, o que demonstrou tratar-se de um processo pelo qual o poder público agiu simplesmente para mitigar uma crise pontual. Após o fim das manifestações, retomou-se paulatinamente a situação de descontentamento, inicialmente percebido na dimensão individual, mas que se consolidou coletivamente.

Mesmo diante dessa regressão ao patamar de desigualdade anterior ao conflito, "os indivíduos frustrados não protestam enquanto não se estabelecem as condições coletivas capazes de agrupá-los e uni-los em torno de uma causa comum e de uma mesma estratégia de reação". (GAIGER, 1999, p.88).

A negativa do Governo Federal em negociar com a categoria, em responder aos seus pleitos, explicitou sobremaneira a necessidade de renegociar o pacto social com o Estado, na medida em que este se posicionou efetivamente como o explorador e colocou em xeque a relação de lealdade existente. “A exploração é um conceito poderoso precisamente porque reúne uma visão de interesses opostos com uma visão da capacidade rudimentar para a resistência" (WRIGHT, 2015, p.159). Essa condição apontou para a irreversibilidade do engajamento que conduziu ao protesto.

Apesar de estarem em posições opostas, a relação existente entre atores societais e atores estatais, no que se refere à permeabilidade destes em relação às reivindicações daqueles, faz com que haja, ainda,

dois tipos de rotinas de protesto e ação direta: "protesto para abrir ou restabelecer negociação", no caso de governos que são menos permeáveis às demandas os movimentos; ou "protestos como parte do ciclo de negociação", mais comuns em situações nas quais atores de governo e movimento são aliados em torno de projetos políticos comuns. (ABERS; SERAFIM; TATAGIBA, 2014, p. 332).

O protesto reúne o arcabouço de performance mais emblemático, do ponto de vista histórico, de ação na interação com os atores estatais, usando como estratégia de pressão a demonstração direta da capacidade de mobilização (SOUSA JÚNIOR, 2017). É também a forma mais pública, midiática e que procura gerar mais visibilidade. 
O abandono da relação foi favorecido ainda pelo ethos, posto que o estilo de vida dos caminhoneiros, acostumados com a dureza da lida diária, envolve a superação das agruras a partir da solidariedade de classe. Com isto, a luta em busca de soluções para os problemas apresentados se traduzia não apenas como uma luta por algo individual, mas por um bem maior que, em última análise, beneficiaria toda a classe.

Como explica Gaiger (1997, p.75):

conjunto de disposições duráveis, o ethos constitui simultaneamente um sistema de crenças, um modo de compreensão e um modelo de comportamento que orientam tanto as opções relativas à vida cotidiana quanto as decisões frente a acontecimentos excepcionais, que geralmente colocam os indivíduos numa conjuntura pessoal de grande tensão, afetiva e cognitivamente perturbadora.

Some-se, ainda, o fato de que o engajamento rumo a uma ação coletiva conflitiva já demonstrara resultado positivo no passado - no caso de 2015 - e a relação entre os atores sociais antagônicos envolvidos poderia ser restabelecida com ganhos efetivos para toda a categoria. E, como subprodutos do engajamento em uma nova manifestação, os caminhoneiros poderiam conquistar mais respeito pela profissão, serem vistos como mais importantes para a sociedade e para a economia do País, além de obterem condições mais dignas de trabalho.

Diante desses fatores, eventuais óbices à ação coletiva conflitiva foram diluídos. A greve de 2015 já havia demonstrado a força da classe mobilizada, uma vez que, como já dito anteriormente, parte significativa da matriz de transporte brasileira utiliza o modal rodoviário, e mesmo para as cargas transportadas por outros modais, os quilômetros finais até o local de destino são feitos, em sua maior parte, por caminhões. "As lutas anteriores e seus (mesmo parcos) resultados revestem-se de uma força de exemplo indiscutível" (GAIGER, 1999, p.76). Com isso, os caminhoneiros tinham plena consciência da sua capacidade de paralisar o País.

Destacam McAdam, Tarrow e Tilly $(2009$, p.25) que "especialmente durante os estágios iniciais de um ciclo de protesto, as escolhas táticas feitas por grupos desafiantes expressam sua identificação com os primeiros insurgentes e sinalizam uma definição mais ampla e inclusiva da luta que surge".

Fatores como imprevisibilidade, irreversibilidade e perda de controle e de autonomia foram minimizados pela organização da mobilização, que envolveu ao menos 11 entidades de classe. Essa composição, associada à capacidade de comunicação e de mobilização dos caminhoneiros - inclusive por meio de aplicativos de redes sociais -, deu até mesmo para aqueles que não tinham 
qualquer vínculo com as organizações a garantia de estarem aderindo a uma luta coletiva.

Quanto ao medo de represálias, sanções e punições, experiências anteriores também já haviam demonstrado que, uma vez iniciado o conflito, a anistia a eventuais punições também estaria na pauta de reivindicações.

\section{Da privação ao conflito}

Ainda na perspectiva de analisar criticamente a paralisação dos caminhoneiros, o marco teórico proposto por Bajoit e Vanhust (2017) é importante lente para compreender as ações coletivas envidadas pelos manifestantes. Desta forma, os eventos em tela precisam ser revisados à luz das 18 condições propostas que integram os "três processos principais de ação coletiva: (1) a passagem da privação para a frustração, (2) a passagem da frustração para a mobilização e (3) a mudança da mobilização para a organização" (BAJOIT; VANHUST, 2017).

\subsection{Da privação à frustração}

Como explicam Bajoit e Vanhust (2017, p. 29), "para que os indivíduos privados de um bem coletivo se sintam frustrados por sua privação, certas condições [18 ao todo] devem ser satisfeitas". Destaque-se que a privação tem dimensão objetiva, enquanto a frustração é subjetiva.

A primeira das condições que favorecem a passagem de privação a frustração é "que o 'bem coletivo' buscado pelo movimento possa ser altamente legitimado pelo modelo cultural vigente". (BAJOIT; VANHUST, 2017, p. 29).

A reivindicação dos caminhoneiros, que em alguns momentos da mobilização pareceu ser difusa, uma vez que envolveu posições políticas, deixou clara a existência de um bem coletivo que lhes fora negado, já demandados em conflitos anteriores e ainda não atendidos. A pauta da redução no preço do combustível, da determinação de um valor mínimo para o frete e da não cobrança do eixo suspenso se traduzem em fatores que, objetivamente, impactam os ganhos dos caminhoneiros e afetam as suas condições mínimas de sustentar a sua família.

Pelo perfil masculino da profissão, conforme já destacado anteriormente, há ainda o sentimento de provedor por parte desses profissionais, o que contribui para o sentimento de frustração, na medida em que os ganhos insuficientes afetam também a sua crença na capacidade de se manter como o arrimo do lar. 
A segunda condição estabelecida pelos autores é que "o 'bem coletivo' reivindicado se integre a um objetivo utópico de longo prazo". (BAJOIT; VANHUST, 2017, p. 32).

Além de sustentar a família, os sentimentos expostos em pesquisa pelos caminhoneiros quanto à imagem que a sociedade tem deles se traduz aqui na luta pela dignidade, por serem vistos como profissionais de protagonismo para que o País avance e não como meros - e até mesmo indesejáveis - coadjuvantes na economia nacional.

A terceira condição é "que os indivíduos, privados desse 'bem coletivo', acreditem que é possível obtê-lo agora". (BAJOIT; VANHUST, 2017, p. 33).

O Brasil já vinha apresentando, desde meados de 2014, cenário de forte recessão econômica que afetou de maneira consistente diversos setores da economia, com a significativa redução no Produto Interno Bruto (PIB). Esse cenário afetou o consumo e, por consequência, a produção. Por estar associado ao processo logístico como área-meio, o setor de transporte foi diretamente impactado.

O Executivo Federal também enfrentava uma crise profunda, na medida em que, apesar de reeleita, a presidente Dilma Rousseff apresentava o mais elevado índice de rejeição entre todos aqueles que já ocuparam o mais alto cargo da República (ARAGÃO, 2015), envolta em escândalos políticos e acusada de má gestão. Esse cenário culminou no impeachment da presidente, em 31 de agosto de 2016. Assumiu definitivamente a Presidência da República o vice-presidente Michel Temer - que já ocupava o cargo interinamente desde 12 de maio daquele ano - , também este envolvido em denúncias, com a legitimidade questionada e herdando a crise econômica em curso.

A crise econômica associada à crise política gerou mudanças na estrutura política que criaram condições favoráveis, com janelas de oportunidade para que os insatisfeitos tivessem mais efetividade ao apresentar a sua pauta de reivindicações (SOUSA JÚNIOR, 2017). Explica Alonso (2009, p.55), que

isso pode ocorrer pelo aumento de permeabilidade das instituições políticas e administrativas às reivindicações da sociedade civil, provocadas por crises na coalizão política no poder; por mudanças na interação política entre o Estado e a sociedade, especialmente a redução da repressão a protestos; e pela presença de aliados potenciais.

A quarta condição que envolve o processo que leva da privação à frustração é "que os indivíduos atribuam a causa da sua privação a um outro ator com o qual tenha relação direta, ou seja, um adversário o qual eles possam atacar". (BAJOIT; VANHUST, 2017, p. 35). 
Diante de todo o contexto, não restam dúvidas de que o Poder Executivo é o responsável por todas as causas da crise. É o ator estatal o único responsável por determinar as políticas econômicas e, em sentido mais amplo, buscar e promover as medidas que possam corrigir os problemas em curso no País.

Órgãos de classe, a exemplo da Ordem dos Advogados do Brasil - OAB, já responsabilizavam o Governo pelos desacertos econômicos. "É preciso que o governo encontre meios de economizar despesas, sem onerar ainda mais os contribuintes, que são atingidos por uma das mais altas cargas tributárias do mundo", afirmou a entidade (RIBEIRO, 2018).

\subsection{Da frustração à mobilização}

Para que indivíduos frustrados se mobilizem, outras condições ainda precisam ser atendidas.

A quinta condição (BAJOIT; VANHUST, 2017, p. 37) rumo à organização é que as soluções individuais para a frustração não sejam fáceis nem difíceis demais. No caso da greve dos caminhoneiros, havia a consciência de que individualmente não teriam a capacidade de gerar qualquer mudança no cenário de privação que conduziu à frustração. Porém, havia também a percepção de que uma ação coletiva teria efeito. Ou seja, individualmente, não seria possível reverter facilmente a posição de desvantagem diante do adversário, mas era possível, por meio da mobilização como classe, encontrar uma solução.

A sexta condição, segundo Bajoit e Vanhust (2017, p. 39), é que os indivíduos "sejam arrastados na mobilização por um ou mais grupos de ativistas a tomarem medidas concretas".

O envolvimento de ao menos 11 entidades de classe e outros grupos informais de caminhoneiros autônomos foi fundamental para o processo que levou à mobilização, na perspectiva de se conquistar mudanças. Como explica Gaiger (1999, p. 75), “atingindo indivíduos predispostos, receptivos a uma palavra e a um gesto de esperança, essas organizações teriam reerguido suas expectativas ao apontarem para a possibilidade de mudança, através da organização e da luta coletiva".

A sétima condição é "que os membros da categoria social frustrada tenham uma unidade anterior ao movimento". (BAJOIT; VANHUST, 2017, p. 39).

Conforme já abordado neste artigo, os caminhoneiros - tanto autônomos quanto assalariados - possuem uma cultura de classe alicerçada em um forte 
senso de adaptação ${ }^{8}$, pela qual compartilham um estilo de vida próprio e contam com a solidariedade como forma de superar os desafios cotidianos. Some-se ainda o fato de que os mecanismos de comunicação mantidos pela categoria relativizam a distância geográfica, o que restou comprovado até mesmo em mobilizações anteriores que pararam diversos Estados de um país com dimensões continentais como o Brasil.

A oitava condição é "que os membros do movimento possam impor uma contribuição importante para o interesse geral, uma contribuição necessária, que permita exercer pressão sobre os adversários". (BAJOIT; VANHUST, 2017, p. 41).

Nessa dimensão, mesmo os caminhoneiros autônomos, que não mantêm qualquer vínculo com entidades de classe, tiveram, por meio da forma como a mobilização foi conduzida, a noção clara da importância da sua adesão ao movimento, contribuindo para a conquista da pauta de reivindicações.

A nona condição estabelecida é que "entre as propostas de negociação e exercício da repressão, o comportamento do adversário tenha importância decisiva". (BAJOIT; VANHUST, 2017, p. 43).

O fato de o Governo Federal ignorar as tentativas de diálogo por parte das organizações de representação de classe, apresentando-se de maneira intransigente, foi decisivo. Suas atitudes de tentar barrar o movimento por meio de ação legal já citada - movida pela Advocacia-Geral da União (AGU) a pedido da Superintendência da Polícia Rodoviária Federal (PRF) - contribuíram para se consolidar na categoria social frustrada a certeza de não haver outro caminho senão o da defecção.

A décima condição (BAJOIT; VANHUST, 2017, p.44) é que a identidade coletiva seja reforçada por afetos. O sentimento de frustração represado encontrou eco na classe, o que, por um lado, despertou o sentimento de poder, na medida em que unidos poderiam ser mais contundentes nas negociações, mas revelou a raiva latente pela condição de privação a que foram submetidos, percebida pela precarização nas condições de trabalho e até mesmo de sustento da própria família. “A gente tá sem condições de trabalhar. Do trabalho que fazemos, $70 \%$ do valor do frete fica em combustível. O resto gastamos com pneus, motoristas, aí no resto não sobra nada", foi o testemunho de Walter Fernandes, caminhoneiro da cidade goiana de Anápolis (VALENTE, 2018).

\footnotetext{
8 "As práticas são entendidas a partir de uma lógica de ação, assente num saber acumulado e difundido através da miríade de interações em que se trama a vida social. [...] As escolhas e iniciativas dos indivíduos de mesma categoria social, seja nas rotinas da vida cotidiana ou perante situações excepcionais, equacionam-se de acordo com o seu ethos de posição, pelo qual os fatos ganham valor e sentido e caucionam-se determinadas formas de agir, em detrimento de outras". (GAIGER, 1999, p. 76).
} 
Como décima primeira condição temos necessidade de "que exista um grupo de referência a ser mobilizado em outras partes do mundo e gere um efeito de contágio". (BAJOIT; VANHUST, 2017, p. 45).

Em período próximo e também na América Latina, um caso guardou forte similitude com a paralisação ocorrida no Brasil. De junho a julho de 2016, o governo do presidente Juan Manuel Santos enfrentou a maior greve de caminhoneiros na história da Colômbia, que paralisou o país por 45 dias. Assim como no Brasil, os caminhoneiros exigiam redução dos preços de combustível e de pedágios, além de fretes melhores. E, da mesma forma, o país fronteiriço sofreu consequências para todos os setores, desde o aumento do preço de alimentos ao desabastecimento de produtos básicos e insumos para a indústria.

A greve terminou com um acordo entre o governo e os sindicatos da categoria, que garantiu a atualização das tarifas de frete, mas o governo manteve as tarifas de combustível e pedágios.

\subsection{Da mobilização à organização}

Por fim, de acordo com Bajoit e Vanhust (2017, p. 46), para que os indivíduos mobilizados sejam organizados, são necessárias outras sete condições.

A décima segunda condição é "que a liderança seja de boa qualidade: unida, honesta, perseverante, independente, combativa e carismática" (BAJOIT; VANHUST, 2017, p. 47).

O movimento em análise teve como características não ter uma liderança centralizadora, mas uma multiplicidade - 11 ao todo - de entidades de representação de classe, ombreadas com grupos e autônomos que se uniram como organização. Em um primeiro momento, isto foi fundamental para conseguir promover uma organização com as dimensões que se observou.

Essa descentralização de lideranças teve como polo organizador o aplicativo de redes sociais WhatsApp, em que grupos de caminhoneiros passaram a se organizar sem a necessidade de um único representante ou mediador.

A décima terceira condição (BAJOIT; VANHUST, 2017, p. 48) afirma que os líderes têm que levar em conta essa diferença e considerar as reivindicações dos mais dominados.

Apesar da descentralização, o início do protesto foi organizado e deflagrado pelas entidades de classe que eram os canais formais de diálogo - ou tentativa deste - com os atores estatais. A pauta de reivindicações abarcou pleitos que eram comuns à categoria e que contemplavam também, em larga medida, aqueles detentores de menor capital social para negociar, como os assalariados, buscando 
melhores condições de trabalho.

A décima quarta condição (BAJOIT; VANHUST, 2017, p. 49) estabelece que, a fim de manter o mais elevado possível o nível de mobilização de suas bases, os líderes têm de propor reivindicações parciais, negociáveis a curto prazo com o adversário, que poderão ser alcançadas com as forças do movimento tal como é agora.

A pauta apresentada, com a redução no preço do diesel e o fim da política de aumentos diários da Petrobras, contemplava pontos que poderiam ser decididos a curto prazo por parte dos atores estatais, ainda que com consequências de médio e longo prazos. O fato é que as conquistas das questões mais imediatas produziriam os efeitos desejados e abririam espaço para sua negociação em questões futuras.

Como décima quinta condição (BAJOIT; VANHUST, 2017, p. 50), os líderes devem saber coletar e administrar "recursos para mobilização": informação, redes, dinheiro...

No início, os custos de alimentação durante a greve ficavam por conta de cada caminhoneiro, o que incluiu a realização de vaquinhas para que fossem providenciadas refeições comunitárias. Porém, uma decisão, tomada rapidamente logo no início da manifestação, foi fundamental para a conquista do apoio popular, o que mais adiante se revelou essencial na manutenção à mobilização. Carros, ambulâncias, ônibus e caminhões com cargas vivas, medicamentos e oxigênio eram liberados. Essa iniciativa rendeu não apenas o apoio moral por parte da sociedade, mas também na forma de doações de água e alimentos.

As informações eram asseguradas por meio dos tradicionais rádios de comunicação instalados nos caminhões, mas sobremaneira pelo uso de aplicativos de redes sociais.

Como décima sexta condição (BAJOIT; VANHUST, 2017, p. 51), a organização deve ser dotada de um bom funcionamento interno.

Nesse aspecto, cada polo de concentração promoveu uma espécie de autoorganização, mas se mantendo, em certa medida, alinhado com os demais polos de paralisação. Após a conquista dos principais pontos da pauta de reivindicações, essa organização foi se diluindo, o que levou ao fim efetivo da paralisação, ainda que, em alguns lugares, houvesse caminhoneiros dispostos a seguir com o protesto.

A décima sétima condição é

que a organização saiba gerir as suas trocas externas, ou seja, saiba definir uma boa política de aliança com outros atores (movimentos sociais ou partidos políticos) capazes de contribuir para a sua ação, e, ao contrário, que saiba claramente demarcar aqueles que podem prejudicar o movimento (sua imagem, suas negociações, suas conquistas). Também é necessário que ela saiba como usar os meios de comunicação de massa de forma 
inteligente. (BAJOIT; VANHUST, 2017, p. 52).

Uma vez mobilizados, os caminhoneiros souberam se valer do interesse da mídia tradicional em cobrir a paralisação para não apenas se comunicar entre si, mas também para atrair o apoio popular para a causa. O movimento aproveitou, ainda, o momento político com um combalido e impopular governo para pedir a saída de Michel Temer da Presidência da República. Com isso,

conseguiu aglutinar setores geralmente distantes ou opostos: da classe média, irritada com os constantes aumentos da gasolina, aos produtores rurais, que reclamam dos prejuízos do setor com o combustível em alta; da esquerda, que aproveitou para criticar a política de preço livre da Petrobras, à direita, que mirou na situação para denunciar o desmonte da petroleira gerado pela corrupção dos governos de esquerda. (ALESSI; BEDINELLI, 2018).

Por fim, a décima oitava condição (BAJOIT; VANHUST, 2017, p.54) é que a organização escolha métodos legítimos de luta. É preferível que o grupo recorra a formas de luta consideradas legítimas de acordo com o modelo cultural vigente. Se o "bem coletivo" não puder ser alcançado sem recorrer a meios ilegítimos, o grupo não se sentirá plenamente autorizado a mobilizar-se.

Os protestos e a ação direta como manifestações, passeatas, ocupação de espaços e a realização de greves compõem um reconhecido e legitimado repertório de luta. Apesar de terem surgido atitudes violentas, o que não é exatamente uma raridade em situações conflitivas, estas foram rechaçadas. O já mencionado apoio popular veio confirmar a anuência dos demais atores societais com os métodos de luta envidados.

\section{Considerações finais}

Como pôde-se observar ao longo deste artigo, a cultura de classe dos caminhoneiros - alicerçada em um forte senso de adaptação, pela qual esses profissionais compartilham um estilo de vida próprio e têm na solidariedade sua principal ferramenta para superar os desafios cotidianos - criou as condições favoráveis para que, diante de uma situação de insatisfação imposta por políticas determinadas pelos atores estatais bem como pela explícita ausência de canais de diálogo, se unissem e parassem o Brasil em torno de uma pauta que contou com o apoio popular, um cenário sem precedentes na história do País. Destaque-se ainda a importância da compreensão desse panorama a partir do ethos de posição, tendo 
em vista que, como nos lembra Gaiger (1997, p.75), este reúne elementos que permitem analisar o comportamento de indivíduos diante de "acontecimentos excepcionais, que [os colocam] numa conjuntura pessoal de grande tensão, afetiva e cognitivamente perturbadora".

Identificamos, a partir da tipologia de classes de Wright, que caminhoneiros autônomos, assalariados (trabalhadores) e empresários donos de transportadoras e locadoras (capitalistas) foram unidos pela pauta de reivindicações, encontrandose, portanto, diante de uma mesma situação de classe, tendo o Estado como o seu vetor comum de exploração.

Diante da perspectiva traçada e da identificação dos atores envolvidos, à luz da Teoria das Ações Coletivas Conflitivas de Guy Bajoit, analisamos as ações envidadas pelos atores societais.

No que se refere à evolução entre a privação e a frustração, o movimento grevista foi legitimado (condições 1 e 2) por uma pauta que envolvia questões cujos ônus e bônus impactavam não apenas a categoria empírica isoladamente, mas se estendiam a toda a sociedade, inclusive no que se refere aos valores, como a precarização das condições dos trabalhadores do setor para manterem dignamente as suas famílias. O cenário de crise política instalado no País, com o recente impeachment da presidente Dilma Rousseff e a legitimidade do presidente Michel Temer questionada, também favoreceu o processo (condições 3 e 4).

Entre a frustração e a mobilização, observou-se a importância do envolvimento de entidades de classe e outros grupos informais, bem como da existência de um ethos de posição (condição 6, 7, 8, 10 e 11) para fazer frente às reiteradas posições intransigentes do Governo, refratárias em relação às tentativas de diálogo (condição 9). Restou evidente que, a partir de ações dos atores estatais em desfavor da categoria, foram estes os principais responsáveis pela "insuficiência de alternativas [que gerou] um descontentamento e uma receptividade à ação coletiva, em razão dos seus resultados efetivos" (GAIGER, 1999, p. 70).

A organização do movimento foi conquistada pela pauta apresentada, o principal elemento agregador dos atores que se opuseram ao Governo (condição 13 e 14). Foi também essa pauta juntamente com a visibilidade criada pela paralisação e a organização descentralizada do movimento - que teve como principal ferramenta agregadora uma mídia social - que conquistaram o apoio popular, dando legitimidade e sustentação às táticas utilizadas pela categoria.

Observa-se, portanto, que, diante de um horizonte de crise, a insatisfação de forma isolada não é suficiente para que haja o engajamento por parte dos indivíduos, porém, a existência de elementos identitários e a organização de classe podem, diante das condições observadas, consolidar a crença de que a conquista é 
possível por meio do conflito, levando efetivamente a uma situação de engajamento na luta. Some-se, ainda, o fato de que os aspectos relacionados à descentralização e ao papel das mídias sociais na mobilização da categoria trazem para as Ciências Sociais novos elementos que contribuem para os estudos acerca dos movimentos sociais e das ações coletivas.

\section{Referências}

ABERS, Rebecca; SERAFIN, Lizandra; TATAGIBA, Luciana.

(2014). Repertórios de Interação EstadoSociedade em um Estado Heterogêneo: a experiência na era Lula. DADOS - Revista de Ciências Sociais, v. 57, n. 2, pp. 325-357.

ALESSI, Gil; BEDINELLI, Talita.

(2018). 0 movimento fragmentado que uniu direita, esquerda e a insatisfação contra Temer. Disponível em: https://brasil.elpais.com/brasil/2018/05/25/p olitica/1527281155_879383.html. Acesso em: 31 set. 2018.

ALONSO, Angela.

(2009). As teorias dos movimentos sociais: Um balanço do debate. Lua Nova, São Paulo, n. 76, pp. 49-86.

ARAGÃ0, Alexandre.

(2015). Reprovação de Dilma cresce e supera a de Collor em 1992. Folha de São Paulo. Disponível em:

https://www1.folha.uol.com.br/poder/2015/0

8/1665135-reprovacao-de-dilma-cresce-esupera-a-de-collor-em-1992.shtml. Acesso em: 5 out. 2018.

BAJ0IT, Guy.

(1988). Exit, Voice, Loyalty... and Apathy: Les réactions individuelles au mécontentement. Revue Française de Sociologie, [s.l.], v. 29, n. 2, p.325-345. Disponivel em: https://www.persee.fr/doc/rfsoc_0035-

2969_1988_num_29_2_2503. Acesso em: 20 set. 2018.

BAJOIT, Guy; VANHUST, Julien.

(2017). Las acciones colectivas conflictivas: El caso del Movimiento Estudantil Chileno. Anuari del Conflicte Social 2016, Barcelona, v. 6, p.2160. Disponível em: http://revistes.ub.edu/index.php/ACS/article/ view/19150/21603. Acesso em: 1º jul. 2018.

BRASIL. AGÊNCIA NACIONAL DO PETRÓLEO, GÁS NATURAL E BIOCOMBUSTIVEIS - ANP.

(2018). Série histórica do levantamento de preçose de margens de comercialização de combustiveis. Disponivel em: www.anp.gov.br/precos-edefesa/234-precos/levantamento-deprecos/868-serie-historica-do-levantamentode-precos-e-de-margens-de-comercializacaode-combustiveis. Acesso em: 5 out. 2018.

CASTILHOS, Roniara; MATOSO, Filipe.

(2018). Governo eliminará tributo que incide sobre diesel e acabará em 2020 com desonerações, diz ministro. Disponivel em: https://g1.globo.com/economia/noticia/deso neracao-da-folha-acabara-para-todos-ossetores-em-2020-diz-fazenda.ghtml. Acesso em: 15 set. 2018.

CONFEDERAÇÃO NACIONAL DO TRANSPORTE - CNT. (2017). Anuário CNT do transporte - estatísticas consolidadas 2017. Brasília: CNT. 229 p. Disponivel em: http://anuariodotransporte.cnt.org.br/2017/Fi le/PrincipaisDados.pdf. Acesso em: 15 set. 2018.

CONFEDERAÇÃO NACIONAL DO TRANSPORTE - CNT. (2016). Pesquisa CNT de perfil dos caminhoneiros 2016. Brasília: CNT. 98 p. Disponível em: http://cms.cnt.org.br/Imagens $\% 20 C N T / P D F s \%$ 20CNT/Pesquisa\%20de\%20Perfil\%20dos\%20Ca minhoneiros/Pesquisa_CNT_de_Perfil_dos_Cam inhoneiros_2016_Completo.pdf. Acesso em: 15 set. 2018. 
CONFEDERAÇÃO NACIONAL DOS TRANSPORTADORES

AUTÔNOMOS - CNTA (Brasil).

(2018). CNTA alerta e pede apoio do governo federal aos transportadores. Disponivel em: https://www.cntabr.org.br/CNTA-ALERTA-EPEDE-APOIO-DO-GOVERNO-FEDERAL-AOSTRANSPORTADORES+84356. Acesso em: 11 set. 2018.

GAIGER, Luiz Inácio.

(1997). Ethos de posição e vida cotidiana. Estudos Leopoldenses, São Leopoldo, v. 33, pp. 69-94.

GAIGER, Luiz Inácio.

(1999). As condições socioculturais do engajamento no MST. Estudos: Sociedade e Agricultura, n. 13, pp. 70-92.

MCADAM, Doug; TARROW, Sidney; TILLY, Charles. (2009). Para mapear o confronto político. Lua Nova, São Paulo, n. 76, p.11-48. Disponível em: http://www.scielo.br/pdf/ln/n76/n76a02.pdf. Acesso em: 23 nov. 2016.

MOREN0, Ana Carolina et al.

(2018). Greve dos caminhoneiros: diferenças e semelhanças do protesto de 2018 com os de 2013 e 2015. Disponivel em: https://g1.globo.com/economia/noticia/greve -dos-caminhoneiros-diferencas-e-semelhancasdo-protesto-de-2018-com-os-de-2013-e2015.ghtml. Acesso em: 5 out. 2018.

PETROBRAS (Brasil).

(2016). Adotamos nova política de preços de diesel e gasolina. Disponível em: http://www.petrobras.com.br/fatos-edados/adotamos-nova-politica-de-precos-dediesel-e-gasolina.htm. Acesso em: 5 set. 2018.
SOUSA JÚNIOR, Gustavo Cruz de.

(2017). O transporte como direito social: o processo político que culminou na aprovação da PEC 90/2011. 2017. 117 f. Dissertação (Mestrado) Curso de Ciências Sociais, Ciências Sociais, Universidade do Vale do Rio dos Sinos Unisinos, São Leopoldo. Disponível em: http://www.repositorio.jesuita.org.br/handle/ UNISINOS/6801. Acesso em: 15 out. 2018.

RIBEIR0, Jeferson.

(2018). OAB diz que greve é culpa da política abusiva de preços dos combustiveis. Disponivel em: https://oglobo.globo.com/economia/oabdiz-que-greve-culpa-da-politica-abusiva-deprecos-dos-combustiveis-22718490. Acesso em: 17 out. 2018.

VALENTE, Jonas.

(2018). Saiba como é dia a dia dos caminhoneiros parados no país. Disponível em: http://agenciabrasil.ebc.com.br/geral/noticia/ 2018-05/saiba-como-é-o-protesto-doscaminhoneiros. Acesso em: 12 out. 2018.

WRIGHT, Erik.

(2015). Análise de classes. Revista Brasileira de Ciência Política. Brasília, 17: 121-163.

\section{Recebido em}

julho de 2019

Aprovado em

abril de 2020 